\title{
Identification of Bioactive Compounds in Polar and Nonpolar Extracts of Araujia sericifera
}

(요 $\odot \odot$

\author{
Authors \\ Martina Palomino-Schätzlein¹, Mary Cecilia Montaño², Pablo V. Escrig ${ }^{3}$, Herminio Boira ${ }^{4}$, Avelino Corma ${ }^{3}$, \\ Antonio Pineda-Lucena', Jaime Primo², Nuria Cabedo
}

\author{
Affiliations \\ 1 Laboratorio de Bioquímica Estructural, Centro de \\ Investigación Príncipe Felipe, Valencia, Spain \\ 2 Centro Ecología Química Agrícola, Instituto Agroforestal \\ Mediterráneo, Universidad Politécnica de Valencia, \\ Valencia, Spain \\ 3 Instituto de Tecnología Química (UPV-CSIC), Valencia, \\ Spain \\ 4 Instituto Agroforestal Mediterráneo, Universidad \\ Politécnica de Valencia, Valencia, Spain
}

\section{Key words}

Araujia sericifera, Asclepiadaceae, metabolite profile, cancer cell lines, GC-MS, NMR spectroscopy

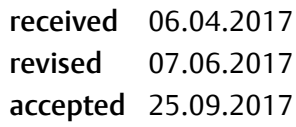

\section{Bibliography}

DOI https://doi.org/10.1055/s-0043-121151

Planta Med Int Open 2017; 4: e93-e103

(c) Georg Thieme Verlag KG Stuttgart · New York

ISSN 2509-9264

\author{
Correspondence \\ Dr. Nuria Cabedo \\ Biomedical Research Institute INCLIVA \\ Menendez Pelayo 4 \\ Valencia, 46010 \\ Spain
}

Tel.: + 34/354/49 49, Fax: +34/354/49 43

ncabedo@uv.es

Details on extraction and properties of the extracts as

Supporting information is available online at http://www.thieme-connect.de/products

\begin{abstract}
Araujia sericifera is a native perennial, climbing laticiferous shrub from South America that is currently naturalized in many other countries. Previous data describe promising properties for $A$. sericifera, but no systematic study of its bioactive compounds and possible medicinal applications has been conducted to date. In the present study, aerial parts of $A$. sericifera (leaves, stems, and fruits) were explored by combining GC-MS and NMR spectroscopy analysis for both nonpolar (hexane) and polar (methanol) extracts. The hexanic extracts contained high amounts of pentacyclic triterpenes including two new metabolites, 3-tigloyl germanicol (18) and 3-tigloyl lupeol (19). The methanolic extracts revealed the presence of luteolin7-glucoside (24), trigonelline (22), and conduritol F (23) as the main constituents. A multivariate study of a meaningful number of extracts allowed us to determine the distribution of compounds inside the plant. A cytotoxic evaluation in vitro showed that both leaf and fruit hexanic extracts presented a moderate activity against human breast carcinoma cell lines (MDA-MB-453 and MCF-7) and human colon carcinoma cell line (HCT-116) by the MTS [3-(4,5-dimethylthiazol-2-yl)-5-(3carboxymethoxyphenyl)-2-(4-sulfophenyl)-2H-tetrazolium] assay.
\end{abstract}

\section{Introduction}

Araujia sericifera Brot. (Asclepiadaceae), also called the bladder flower, is a native perennial, climbing laticiferous shrub from South America that was introduced to other countries as an exotic ornamental plant. Currently, it is naturalized in Europe, South Africa, North America, Australia, and New Zealand. In the Mediterranean coastline, it competes with different crops, such as citrus trees, for water and nutrients $[1,2]$. A. sericifera was reported to possess emetic, analgesic, antihistaminic, and anti-inflammatory proper- ties [3-5]. Its seeds were described to exert toxicity on the central nervous system [3]. Its fruits contain luteolin-7-glucoside, serotonin [3], lupeol-3-cinnamate, and germanicol-3-acetate [4]. Nevertheless, despite the promising properties of $A$. sericifera, there is no systematic study of its chemical composition.

In a plant, different classes of secondary metabolites exert individual biological functions. They accumulate in specific tissues playing different roles in physiological processes or ecological interactions [6]. Metabolic profiling of different plant organs (root, shoot, 
leaves, etc.) has been a tool to achieve better authentication and chemotaxonomic analyses of plants [7]. In line with this, the metabolic composition of the different organs of $A$. sericifera, with a broad tolerance for environmental conditions, has attracted our attention. Several methods exist to detect and quantify plant metabolites, such as NMR spectroscopy- and MS-based techniques, the major analytical tools used for metabolite profile studies. Both analytical techniques are considered complementary to obtain optimal results, each with its own particular advantages [8]. The aim of this study was to analyze the composition and cytotoxic properties of both nonpolar (hexane) and polar (methanol) extracts of the three aerial parts of $A$. sericifera (leaves, fruits, and stems) using GC-MS and NMR spectroscopy methods in conjunction with multivariate statistical analyses in order to explore this poorly studied plant.

\section{Results and Discussion}

Polar and nonpolar metabolites were extracted by an automated Soxhlet extraction (Soxtec) of each aerial plant part with $n$-hexane and, subsequently, methanol to give the hexanic and methanolic extract, respectively. The leaves, stems, and fruits extracted with $\mathrm{n}$-hexane gave extract yields (w/w), which were $5.6 \%$ for both leaves and fruits, and $2.2 \%$ for stems. The subsequent extraction with methanol gave higher extract yields for leaves and stems ( $21.0 \%$ and $16.4 \%$, respectively) than for fruits (11.0\%). In the hexanic extracts, 20 different metabolites were identified by a combination of GC-MS (after trimethylsilyl derivatization) and 1D and 2D NMR spectroscopy. These nonpolar metabolites consisted of fatty esters (FEs), fatty acids [FAs: palmitic (1), linoleic acid (2), oleic acid (3), stearic acid (4)], squalene (5), n-alkanes (6-8), $\beta$-sitosterol (9), $\beta$-amyrin-3-acetate (12, oleanane type), and chiefly triterpen-3-ols and/or their esters, such as lupeol (lupane type) and germanicol esters (oleanane type), and compounds 10, 11, and 13-19. For an unequivocal characterization of the lupeol and germanicol esters, an aliquot of the fruit hexanic extract was subjected to silica gel column chromatography and semipreparative reversed-phase HPLC purification. Several pentacyclic triterpenes could be isolated, including to new compounds, 3-O-tigloyl germanicol (18, oleanane type) and 3-O-tigloyl lupeol (19, lupane type) (• Fig. 1). The structure elucidation of $\mathbf{1 8}$ and $\mathbf{1 9}$ was carried out by GC-MS, 1D and 2D NMR spectroscopy, and UPLC-Q-TOF analysis. The ${ }^{1} \mathrm{H}$ and ${ }^{13} \mathrm{C}$ NMR spectra of compound 18 and 19 ( $\triangleright$ Table 1 and Fig. 3S, 4S, and 5S, Supporting Information) exhibited the typical signals of an (E)-tigloyl group; e.g., for compound 19 at $\delta_{\mathrm{H}}$ (ppm) 6.83 (q, J = $7.1 \mathrm{~Hz}, \mathrm{H}-33), 1.83\left(\mathrm{~s}, \mathrm{H}_{3}-35\right)$ and 1.78 (d, $\left.\mathrm{J}=7.1 \mathrm{~Hz}, \mathrm{H}_{3}-34\right)$ and $\delta_{\mathrm{C}}(\mathrm{ppm}) 167.9$ (CO), 136.5 (CH-33), 129.3 (C-32), $14.3\left(\mathrm{CH}_{3}-34\right)$ and $12.1\left(\mathrm{CH}_{3}-35\right)$. The $\mathrm{HMBC}$ spectrum of these compounds also showed a correlation from $\mathrm{H}-3\left(\delta_{\mathrm{H}} 4.51\right.$ ppm) to the carbonyl carbon (CO) of the tigloyl group at $\delta_{C} 167.9$ ppm. The GC-MS data also displayed a characteristic MS fragmentation of oleanane and lupane skeletons for compounds $\mathbf{1 8}$ and $\mathbf{1 9}$, respectively. Intense fragment ions were observed at $\mathrm{m} / \mathrm{z} 204,189$, and 177 for compound $\mathbf{1 8}\left(\Delta^{18}\right.$-oleanene with a methyl group at C-17). However, compound 19 with a C-20-29 double bond and a methyl group at $\mathrm{C}-17$ presented a main peak at $\mathrm{m} / \mathrm{z} 207$ $\left(\left[\mathrm{C}_{14} \mathrm{H}_{23} \mathrm{O}\right]^{+},[\mathrm{A}+\mathrm{B}]^{+}\right.$rings $)$and at $\mathrm{m} / \mathrm{z} 189\left(\left[\mathrm{C}_{14} \mathrm{H}_{21}\right]^{+},[\mathrm{A}+\mathrm{B}]^{+}\right.$ rings- $\mathrm{H}_{2} \mathrm{O}$ ). Fragmentation peaks at $\mathrm{m} / \mathrm{z} 508$, 493, and 408 corresponded to the molecular ion peaks $[\mathrm{M}]^{+},\left[\mathrm{M}-\mathrm{CH}_{3}\right]^{+}$, and $[\mathrm{M}$-tiglic acid $]^{+}$, respectively. The HRESIMS analysis for compounds 18 and 19 displayed an ion peak at $\mathrm{m} / \mathrm{z} 409.3832$ or 409.3829 [ $\left(\mathrm{M}-\mathrm{C}_{5} \mathrm{H}_{7} \mathrm{O}\right.$ $\left.\left.\mathrm{H}_{2} \mathrm{O}\right)+\mathrm{H}\right]^{+}$, respectively, which suggests the molecular formula $\mathrm{C}_{30} \mathrm{H}_{48}$ (calcd. 409.3829) for both compounds corresponding to the loss of the tigloyl group and one water molecule.

Known triterpenes were also identified by making a direct comparison of their NMR spectroscopic and GC-MS data with those reported in the literature, including germanicol (10) [9], lupeol (11) [10], $\beta$-amyrin-3-acetate (12) [11], germanicol-3-acetate (13) [12], lupeol-3-acetate (14) [9], lupeol-3-cinnamate (15) [13], germanicol3-propionate (16), and germanicol-3-butyrate (17) [14] (• Fig. 1). Among them, lupeol-3-acetate (14), germanicol-3-propionate (16), and germinacol-3-butyrate (17) were identified in A. sericifera for the first time. A representative GC-MS chromatogram section of the three plant aerial parts containing principally triterpen3-ols and/or their esters is drawn in $>\mathbf{F i g}$. $\mathbf{2 a}$. In $>\mathbf{F i g}$. $\mathbf{2 b}$, the ${ }^{13} \mathrm{C}$ NMR spectra of the hexanic extracts of leaves, stems, and fruits are depicted. The acquisition of ${ }^{13} \mathrm{C}$ spectra seemed an optimal choice for these nonpolar fractions since the ${ }^{1} \mathrm{H}$ NMR spectra were highly overlapped due to the high amounts of alkanes and enough sample amount was available to obtain a good signal/noise ratio in the less sensitive ${ }^{13} \mathrm{C}$ spectroscopy. It is worth mentioning that $\beta$-amyrin-3-acetate (12), present in very small amounts in leaves and stems, was only detected by the most sensitive technique GC-MS but not in the NMR spectra. In addition, only general signals of alkanes and FAs were assigned in the NMR spectra due to overlapping. On the other hand, NMR spectroscopy allowed for the quantification of several nonvolatile compounds such as long-chain FEs that could not be analyzed by GC-MS. Similarly, the quantification of lupeol-3-cinnamate (15) was only feasible by NMR spectroscopy since its peak overlapped with germanicol-3-propionate (16) in the GC-MS chromatogram ( $t_{R}=26.09 \mathrm{~min}$ ). Relative percentages of metabolites from the hexanic extracts determined by GC-MS and ${ }^{13} \mathrm{C}$ NMR in leaves, stems, and fruits are shown in Fig. 65 and 7S, Supporting Information. Thus, we found that the combination of NMR and GC-MS is optimal for the detection of nonpolar metabolites in $A$. sericifera.

Concerning the polar fraction, 25 metabolites were identified in the methanolic extracts using GC-MS (after methoximation and trimethylsilyl derivatization) and NMR spectroscopy. In order to unambiguously identify several polar metabolites, an aliquot of the fruit methanolic extract was subjected to a solid-phase extraction (SPE) $\mathrm{C}_{18}$ cartridge and was eluted firstly with $100 \% \mathrm{H}_{2} \mathrm{O}$, followed by $100 \% \mathrm{MeOH}$. The methanolic fraction (F-2) was further purified by reversed-phase HPLC to give viburnitol (21, $\left.\mathrm{SF}_{\text {meth }} 2-1\right)$ [15], trigonelline (22, $\left.\mathrm{SF}_{\text {meth }} 2-2\right)$ [16], and conduritol $\mathrm{F}\left(\mathbf{2 3}, \mathrm{SF}_{\text {meth }} 2-3\right.$, also known as L-leuchanthemitol) [17] ( Fig. 1). The GC-MS analysis of the whole extracts also detected viburnitol (21), malate (37), L-asparagine (31), sucrose (38), glucose (40), fructose, and myoinositol. A representative GC-MS chromatogram of the fruit methanolic extract is shown in Fig. 8S, Supporting Information. NMR spectroscopy confirmed the presence of metabolites detected by MS and further allowed for the identification of luteolin-7-glucoside (24), serotonin (25), allantoin (26), choline (28), and malate (37). In fact, luteolin-7-glucoside (24) and serotonin (25) were pre- 


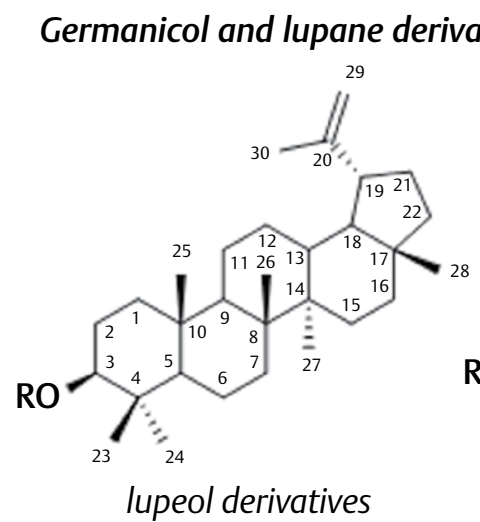

$(11,14,15,19)$

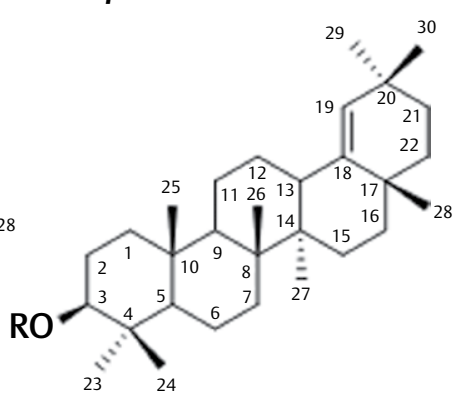

germanicol derivatives

$(10,13,16,17,18)$

\begin{tabular}{|l|c|}
\hline Compound & $\mathrm{R}$ \\
\hline Germanicol (10) & $\mathrm{H}$ \\
\hline \begin{tabular}{l} 
Lupeol (11) \\
\hline Germanicol-3-acetate (13)
\end{tabular} & $\mathrm{CH}_{3} \mathrm{CO}$ \\
\hline Lupeol-3-acetate (14) & $\mathrm{PhCH}=\mathrm{CHCO}$ \\
\hline Lupeol-3-cinnamate (15) & $\mathrm{CH}_{3} \mathrm{CH}_{2} \mathrm{CO}$ \\
\hline Germanicol-3-propionate (16) & $\mathrm{CH}_{3}\left(\mathrm{CH}_{2}\right)_{2} \mathrm{CO}$ \\
\hline Germanicol-3-butyrate (17) & $\mathrm{H}_{3} \mathrm{C}_{34}^{33}{ }_{35}^{32} \mathrm{CH}_{33}$ \\
\hline 3-O-Tigloyl-germanicol (18) & \\
\hline 3-O-Tigloyl-lupeol (19) & \\
\hline
\end{tabular}

Metabolites from methanolic extracts<smiles>O[C@H]1C[C@@H](O)[C@H](O)[C@H](O)[C@H]1O</smiles>

Viburnitol (21)<smiles></smiles>

Trigonelline (22)<smiles>OC1C=C[C@@H](O)[C@H](O)C1O</smiles>

Conduritol F (23)<smiles>O=c1cc(-c2ccc(O)c(O)c2)oc2cc(OC3OC(CO)C4OC3C(O)C4O)cc(O)c12</smiles>

Luteolin-7-glucoside (24)

Fig. 1 Nonpolar secondary metabolites identified in hexanic extracts, germanicol type and lupeol type, and polar metabolites from methanolic extracts of $A$. sericifera. 
- Table $1{ }^{1} \mathrm{H}$ and ${ }^{13} \mathrm{C}$ NMR data for 18 and 19 in $\mathrm{CDCl}_{3}$ ( $\delta$ in ppm, $\mathrm{J}$ in $\mathrm{Hz}$ ).

\begin{tabular}{|c|c|c|c|c|}
\hline & \multicolumn{2}{|c|}{18} & \multicolumn{2}{|c|}{19} \\
\hline Position & $\begin{array}{c}\delta_{c} \\
\text { (mult.) }\end{array}$ & $\begin{array}{c}\delta_{\mathrm{H}} \\
(\mathrm{J} \text { in } \mathrm{Hz})\end{array}$ & $\begin{array}{c}\delta_{\mathrm{C}} \\
\text { (mult.) }^{\mathrm{a}}\end{array}$ & $\begin{array}{c}\delta_{H} \\
(J \text { in } \mathrm{Hz})\end{array}$ \\
\hline $1 \mathrm{a}$ & $37.3\left(\mathrm{CH}_{2}\right)$ & $1.50, \mathrm{~m}$ & $38.4\left(\mathrm{CH}_{2}\right)$ & $1.69, \mathrm{~m}$ \\
\hline $1 b$ & & & & $1.00, \mathrm{~m}$ \\
\hline $2 a$ & $23.4\left(\mathrm{CH}_{2}\right)$ & $1.65, \mathrm{~m}$ & $23.7\left(\mathrm{CH}_{2}\right)$ & $1.47, \mathrm{~m}$ \\
\hline $2 b$ & & $1.14, \mathrm{~m}$ & & $1.08, \mathrm{~m}$ \\
\hline 3 & $80.7(\mathrm{CH})$ & $\begin{array}{c}4.52, d \\
(6.4)\end{array}$ & $80.9(\mathrm{CH})$ & $\begin{array}{c}4.51, \mathrm{dd} \\
(5.9)\end{array}$ \\
\hline 4 & $37.7(\mathrm{C})$ & - & $38.1(\mathrm{C})$ & - \\
\hline 5 & $55.2(\mathrm{CH})$ & $0.8, \mathrm{~m}$ & $55.4(\mathrm{CH})$ & $0.80, \mathrm{~m}$ \\
\hline $6 a$ & $17.9\left(\mathrm{CH}_{2}\right)$ & $1.60, \mathrm{~m}$ & $18.2\left(\mathrm{CH}_{2}\right)$ & $1.5, \mathrm{~m}$ \\
\hline $6 b$ & & $1.38, \mathrm{~m}$ & & $1.45, \mathrm{~m}$ \\
\hline $7 a$ & $34.4\left(\mathrm{CH}_{2}\right)$ & $1.55, \mathrm{~m}$ & $34.2\left(\mathrm{CH}_{2}\right)$ & $1.4, \mathrm{~m}$ \\
\hline $7 b$ & & $1.41, \mathrm{~m}$ & & \\
\hline 8 & $43.1(\mathrm{C})$ & - & $40.9(C)$ & - \\
\hline 9 & $51.0(\mathrm{CH})$ & $1.33, \mathrm{~m}$ & $50.3(\mathrm{CH})$ & $1.35, \mathrm{~m}$ \\
\hline 10 & $37.2(\mathrm{C})$ & - & $37.1(\mathrm{C})$ & - \\
\hline $11 a$ & $20.9\left(\mathrm{CH}_{2}\right)$ & $1.55, \mathrm{~m}$ & $21.0\left(\mathrm{CH}_{2}\right)$ & $1.5, \mathrm{~m}$ \\
\hline $11 \mathrm{~b}$ & & $1.40, \mathrm{~m}$ & & \\
\hline $12 a$ & $26.0\left(\mathrm{CH}_{2}\right)$ & $1.64, \mathrm{~m}$ & $25.1\left(\mathrm{CH}_{2}\right)$ & $1.60, \mathrm{~m}$ \\
\hline $12 b$ & & $1.25, \mathrm{~m}$ & & \\
\hline 13 & $38.2(\mathrm{CH})$ & $\begin{array}{c}2.26, \mathrm{~d} \\
(11.0)\end{array}$ & $38.1(\mathrm{CH})$ & $1.66, \mathrm{~s}$ \\
\hline 14 & 40.5 (C) & - & $43.0(C)$ & - \\
\hline $15 a$ & $27.2\left(\mathrm{CH}_{2}\right)$ & $1.72, \mathrm{~m}$ & $27.4\left(\mathrm{CH}_{2}\right)$ & $1.46, \mathrm{~m}$ \\
\hline $15 b$ & & $1.25, \mathrm{~m}$ & & $1.00, \mathrm{~m}$ \\
\hline 16 & $38.2\left(\mathrm{CH}_{2}\right)$ & $1.70, \mathrm{~m}$ & $35.6\left(\mathrm{CH}_{2}\right)$ & $1.5, \mathrm{~m}$ \\
\hline 17 & $34.2(\mathrm{C})$ & - & $42.8(\mathrm{C})$ & - \\
\hline 18 & $167.5(C)$ & - & $48.3(\mathrm{CH})$ & $1.35, \mathrm{~m}$ \\
\hline 19 & $129.7(\mathrm{CH})$ & $4.86, \mathrm{~s}$ & $48.0(\mathrm{CH})$ & $\begin{array}{c}2.38, \text { ddd } \\
(10.0)\end{array}$ \\
\hline 20 & $32.2(\mathrm{C})$ & & $151.0(\mathrm{C})$ & - \\
\hline $21 a$ & $33.3\left(\mathrm{CH}_{2}\right)$ & $1.60, \mathrm{~m}$ & $29.8\left(\mathrm{CH}_{2}\right)$ & $1.92, \mathrm{~m}$ \\
\hline $21 \mathrm{~b}$ & & $1.38, \mathrm{~m}$ & & $1.30, \mathrm{~m}$ \\
\hline $22 a$ & $37.3\left(\mathrm{CH}_{2}\right)$ & $1.49, \mathrm{~m}$ & $40.0\left(\mathrm{CH}_{2}\right)$ & $1.45, \mathrm{~m}$ \\
\hline $22 b$ & & & & $1.22, \mathrm{~m}$ \\
\hline 23 & $28.9\left(\mathrm{CH}_{3}\right)$ & $0.86, \mathrm{~s}$ & $28.1\left(\mathrm{CH}_{2}\right)$ & $0.86, \mathrm{~s}$ \\
\hline 24 & $16.6\left(\mathrm{CH}_{3}\right)$ & $0.87, \mathrm{~s}$ & $16.7\left(\mathrm{CH}_{3}\right)$ & $0.89, \mathrm{~s}$ \\
\hline 25 & $16.4\left(\mathrm{CH}_{3}\right)$ & $0.91, \mathrm{~s}$ & $16.2\left(\mathrm{CH}_{3}\right)$ & $0.87, \mathrm{~s}$ \\
\hline 26 & $15.8\left(\mathrm{CH}_{3}\right)$ & $1.08, \mathrm{~s}$ & $16.0\left(\mathrm{CH}_{3}\right)$ & $1.02, \mathrm{~s}$ \\
\hline 27 & $14.3\left(\mathrm{CH}_{3}\right)$ & $0.74, \mathrm{~s}$ & $14.5\left(\mathrm{CH}_{3}\right)$ & $0.98, \mathrm{~s}$ \\
\hline 28 & $25.0\left(\mathrm{CH}_{3}\right)$ & $1.02, \mathrm{~s}$ & $18.0\left(\mathrm{CH}_{3}\right)$ & $0.80, \mathrm{~s}$ \\
\hline $29 a$ & $28.8\left(\mathrm{CH}_{3}\right)$ & $0.97, \mathrm{~s}$ & $109.3\left(\mathrm{CH}_{2}\right)$ & $\begin{array}{c}4.69, \mathrm{~d} \\
(5.8)\end{array}$ \\
\hline $29 b$ & & & & $4.57, \mathrm{~s}$ \\
\hline 30 & $31.2\left(\mathrm{CH}_{3}\right)$ & $0.94, \mathrm{~s}$ & $19.3\left(\mathrm{CH}_{3}\right)$ & $1.69, \mathrm{~s}$ \\
\hline 31 & 167.7 (CO) & - & $167.9(\mathrm{CO})$ & - \\
\hline 32 & $129.1(\mathrm{C})$ & - & $129.3(\mathrm{C})$ & - \\
\hline 33 & $136.1(\mathrm{CH})$ & $\begin{array}{c}6.84, \mathrm{q} \\
(5.8)\end{array}$ & $136.5(\mathrm{CH})$ & $\begin{array}{c}6.83, \mathrm{q} \\
(7.1)\end{array}$ \\
\hline 34 & $14.1\left(\mathrm{CH}_{3}\right)$ & $\begin{array}{c}1.79, \mathrm{~d} \\
(5.8)\end{array}$ & $14.3\left(\mathrm{CH}_{3}\right)$ & $\begin{array}{c}1.78, \mathrm{~d} \\
(7.1)\end{array}$ \\
\hline 35 & $11.9\left(\mathrm{CH}_{3}\right)$ & $1.83, \mathrm{~s}$ & $12.1\left(\mathrm{CH}_{3}\right)$ & $1.83, \mathrm{~s}$ \\
\hline
\end{tabular}

viously identified from the leaves and stems of $A$. sericifera [3], whereas virbutinol (21), trigonelline (22), conduritol $F(23)$, and allantoin (26) were found in this plant for the first time. Representative ${ }^{1} \mathrm{H}$ NMR spectra of the leaf, stem, and fruit methanolic extracts are depicted in > Fig. 3, along with an assignment of the most significant metabolites.

In order to gain insight about how the identified compounds were distributed in the different plant parts, they were quantified from leaves, stems, and fruits (Fig. 9S, Supporting Information), and an unsupervised multivariate analysis in the form of principal component analysis (PCA) was performed. The resulting score and loading plots from the PCA of the GC-MS and ${ }^{13} \mathrm{C}$ NMR data from nonpolar extracts are represented in $>$ Fig. 4 . While the score plot ( $\triangleright$ Fig. 4a and c) gives information about how the different samples cluster based on their metabolic composition, the loading plot ( $\triangleright$ Fig. 4b and d) indicates which compounds are more present in each sample group. As we can see, a similar clustering was obtained by both analytical techniques. In both cases, large amounts of alkanes, saturated fatty acids/esters were associated with the stem extracts, while larger quantities of unsaturated fatty acids/esters, linoleic and linolenic acids and derivatives were found in the leaves. Cis-polyisoprene (20) and squalene (5) were identified only in the leaves, which also had greater amounts of $\beta$-sitosterol (9) and lupeol (11) than the other aerial parts. However, fruit extracts stood out for possessing germanicol (10) and large quantities of triterpene esters including germanicol-3-acetate (13), lupeol-3-acetate (14), lupeol-3-cinnamate (15), germanicol-3-propionate (16), 3-Otigloyl germanicol (18), and 3-O-tigloyl lupeol (19).

For the polar metabolites, we quantified the identified compounds by ${ }^{1} \mathrm{H}$ NMR in the same set of samples of the three plant aerial parts and also performed PCA to compare the metabolite contents. The resulting score and loading plots are represented in - Fig. 5. We observed that the stem extracts stand out for their high content in sugars such as sucrose (38) and glucose (40). Larger amounts of branched amino acids such as isoleucine (32), leucine (33). and valine (36) proved to be characteristic of the leaf extracts. Flavonoid luteolin-7-glucoside (24) was also significantly increased in the leaves. The metabolic composition of fruits differed vastly from that of the stems and leaves, standing out for high concentrations of viburtinol (21), trigonelline (22), conduritol F (23), serotonin (25), choline (28), succinate (43), or fumarate (30).

Thus, our study lays bare that $A$. sericifera, a climbing weed that competes with crops, contains several bioactive compounds with beneficial applications. Accordingly, nonpolar extracts possess high levels of triterpen-3-ol and their esters, especially in leaves and fruits, respectively. Naturally occurring and synthetic pentacyclic triterpenes exhibit a variety of unique biological activities, including antitumor, antiviral, antidiabetic, anti-inflammatory, antimicrobial, antiparasitic, cardio-, hepato- and gastro-protection, and analgesic and wound healing effects, among others. In fact, they are receiving ever-increasing interest as therapeutic agents in pharmacological research [18]. Lupeol (11) has the ability to inhibit $\alpha$ amylases [19] and $\alpha$-glucosidases [20] and possesses hypoglycemic and antidiabetic properties. In addition, germanicol (10) and lupeol (11) display anti-inflammatory [21] and antidyslipidemic effects [19]. Among the polar secondary metabolites of $A$. sericifera, trigonelline (22), which is abundant in leaves, has shown hypogly- 

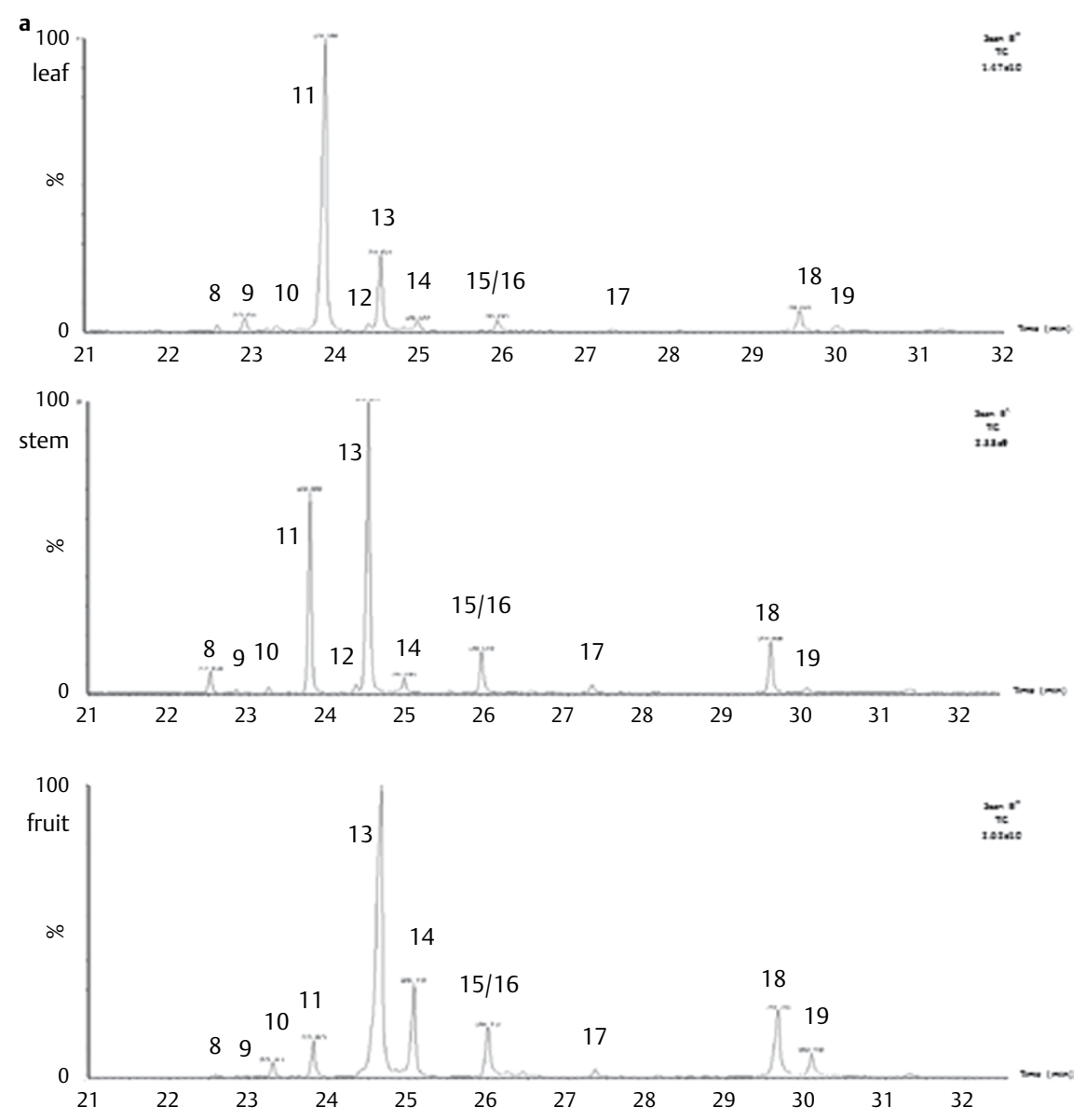

b

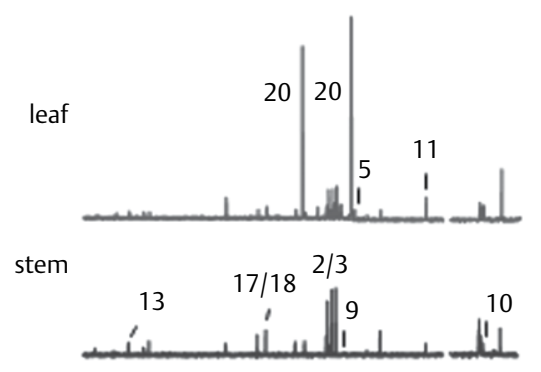

fruit
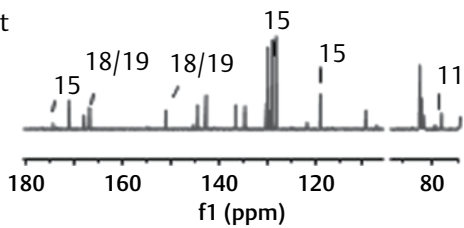

- Fig. 2 Identification of nonpolar metabolites from leaves, stems, and fruits of A. sericifera containing principally triterpen-3-ols and/or their esters. a A section of total ion GC-MS chromatograms of the TMS-derivatized hexanic extracts. $\mathbf{b}{ }^{13} \mathrm{C} \mathrm{NMR}$ spectra of hexanic extracts at $600 \mathrm{MHz}$. Assignments: 8, tritiacontane; 9, $\beta$-sitosterol; 10, germanicol; 11, lupeol; 12, $\beta$-amyrin-3-acetate; 13, germanicol-3-acetate; 14, lupeol-3-acetate; 15 , lupeol-3-cinnamate; 16, germanicol-3-propionate; 17, germanicol-3-butyrate; 18, 3-O-tigloyl germanicol; 19, 3-O-tigloyl lupeol; 20, cis-polyisoprene.

cemic, hypocholesterolemic, antitumoral, and antiseptic properties besides playing an essential role in the resistance process of plants against several pathogens [22]. Concerning the two natural cyclitols viburnitol (21) and conduritol F (23), compound 21 acts as a glycosidase inhibitor [23] and compound $\mathbf{2 3}$ has potential in the treatment of metastatic cancer and diabetes because of its 


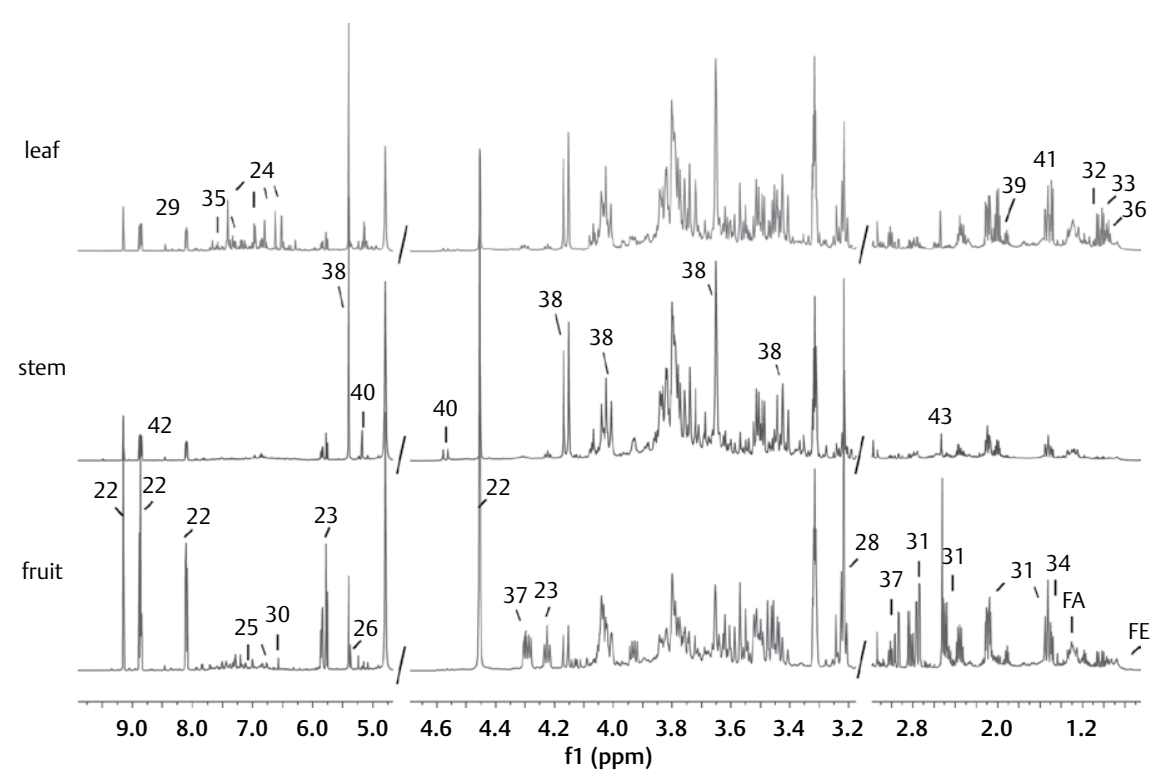

- Fig. 3 Representative ${ }^{1} \mathrm{H}$ NMR spectra of leaf, stem, and fruit methanolic extracts of $A$. sericifera. Metabolite keys are given in Table 1S, Supporting Information. Assignments: 22, trigonelline; 23, conduritol F; 24, luteolin-7-glucoside; 25, serotonin; 26, allantoin; 28, choline; 29, formate; $\mathbf{3 0}$, fumarate; 31, L-asparagine; 32, L-isoleucine; 33, L-leucine; 34, L-threonine/lactate; 35, L-tryptophan; 36, L-valine; 37, malate; 38, sucrose; 39, $\gamma$-butyric acid; $\mathbf{4 0}$, glucose; $\mathbf{4 1}$, L-alanine; $\mathbf{4 2}$, adenosine; $\mathbf{4 3}$, succinate; FA, fatty acids; $\mathbf{F E}$, fatty esters. $\mathbf{m}$ Please remove ,,a“ from figure, as there is no ,,b“正

ability to inhibit type I $\alpha$-glucosidase [24]. Luteolin-7-O-glucoside (24) has an important nutraceutical application value thanks to its numerous biological properties, including antioxidant activity [25].

In order to evaluate the cytotoxic activity of $A$. sericifera plant extracts and the pentacyclic triterpenes, MTS assays were performed on human breast carcinoma (MDA-MB-453 and MCF7) and human colon carcinoma (HCT-116) cell lines. As a result, the fruit hexanic extract of $A$. sericifera showed a significant cell growth reduction of HCT-116 and MCF-7 cells, while the effect produced by leaf extracts was more modest but with a higher impact against the aggressive cell line MDA-MB-453 ( $\mathbf{F i g . 6}$ a and b). These results are coherent with the fact that the most bioactive compounds reported from nonpolar extracts occurred in these two plant organs. The cytotoxic activity for fruit hexanic extracts may be attributed to germanicol derivatives [26]. In leaves, high amounts of lupeol, a known inhibitor of proliferation [27], can induce cytotoxicity. In order to find out if 3-O-tigloyl lupeol (19) contributes to the cytotoxic activity of the nonpolar fruit and leaf extracts, it was semisynthesized by esterification between lupeol and tiglic acid. Nevertheless, compounds $\mathbf{1 5}$ and $\mathbf{1 9}$ did not show significant cell growth reduction at the tested concentrations, which was only obtained for lupeol (11) against the three cell lines ( Fig. 6c). 3-O-Tigloyl germanicol (18) could not be assayed as not enough quantity was available. In the case of polar extracts of A. sericifera, a significant growth reduction was only detected in leaf extracts ( $\vee$ Fig. $6 \mathbf{6 d}$ ). This effect may be mainly due to the presence of luteolin-7-O-glucoside, which was previously described to inhibit proliferation of cancer cells [28].

In summary, our study of different aerial parts of $A$. sericifera by GC-MS and NMR spectroscopy allowed for the identification of in- teresting compounds with potential pharmaceutical and/or industrial uses. Several secondary metabolites have been identified in this plant for the first time, and two new triterpen-3-ol esters, 3-Otigloyl germanicol (18) and 3-O-tigloyl lupeol (19), were characterized from the hexanic extracts. A systematic analysis of an array of plants showed that the major bioactive compounds were distributed in fruits and leaves. Accordingly, the new compound 3-Otigloyl lupeol (19) did not show any cytotoxicity against the cancer cell lines at the tested concentrations. Therefore, the moderate cytotoxicity exhibited for both fruit and leaf hexanic extracts against the breast cancer model MCF-7 and the human colon carcinoma HCT-116 may be attributed to lupeol (11).

\section{Materials and Methods}

\section{Cell lines, chemicals, and biochemicals}

MDA-MB-453, MCF-7 (human breast carcinomas), and HCT-116 (human colon carcinoma) cell lines were provided by M. Orzáez (CIPF) [29], and grown at $37{ }^{\circ} \mathrm{C}$ in a humidified $5 \% \mathrm{CO}_{2}, 95 \%$ air incubator. All the standard compounds and reagents (purities $\geq 94 \%$ ) were purchased from Sigma-Aldrich with the exception of N,Obis(trimethylsilyl)-trifluoroacetamide (BSTFA) with $1 \%$ trimethylchlorosilane (TMCS) (purity $>98 \%$ ), which was purchased from Acros. Hexane, dichloromethane, methanol, and pyridine were analytical grade and purchased from Scharlab SL. Chloroform-d with $0.05 \% \mathrm{v} / \mathrm{v}$ trimethylsilane (TMS), methanol- $\mathrm{d}_{4}$, and trimethylsilyl2,2,3,3-tetradeuteropropionic acid (TSP; purities >99\%)were purchased from Deutero $\mathrm{GmbH}$. 
a
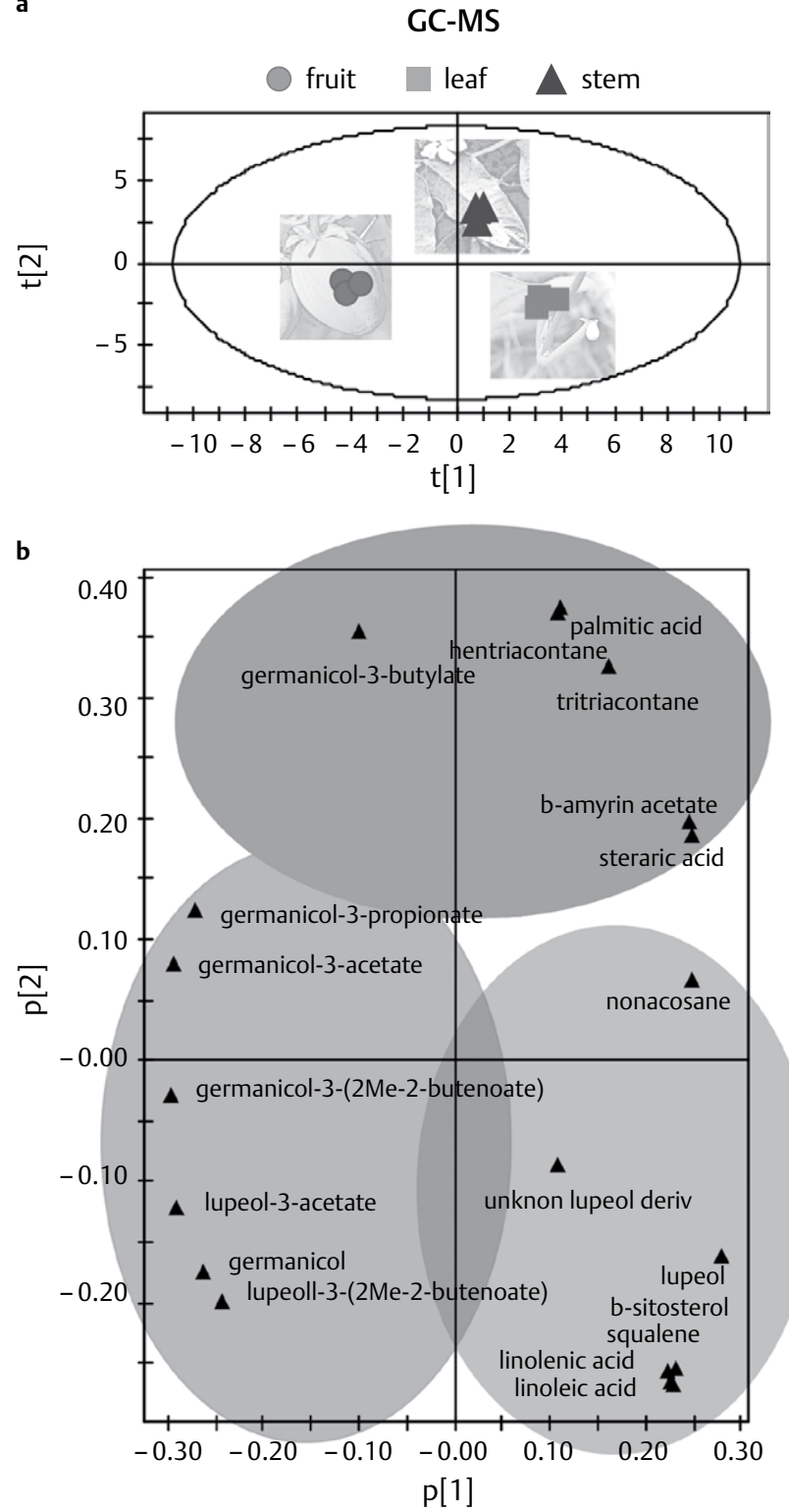

c

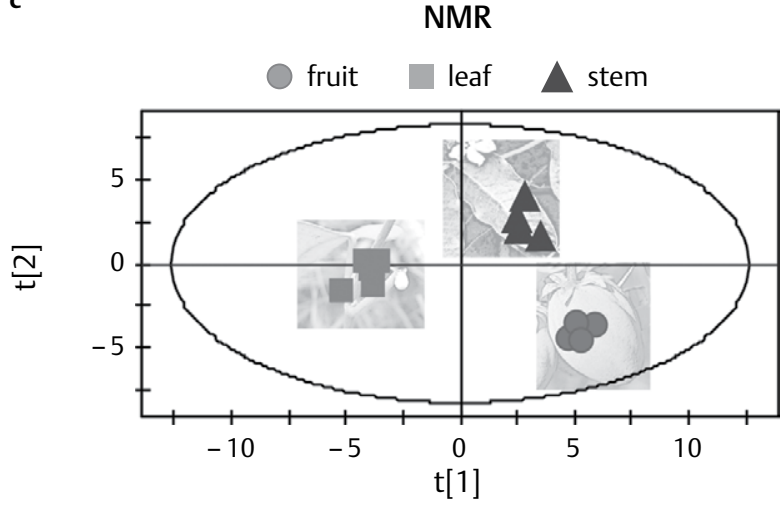

d

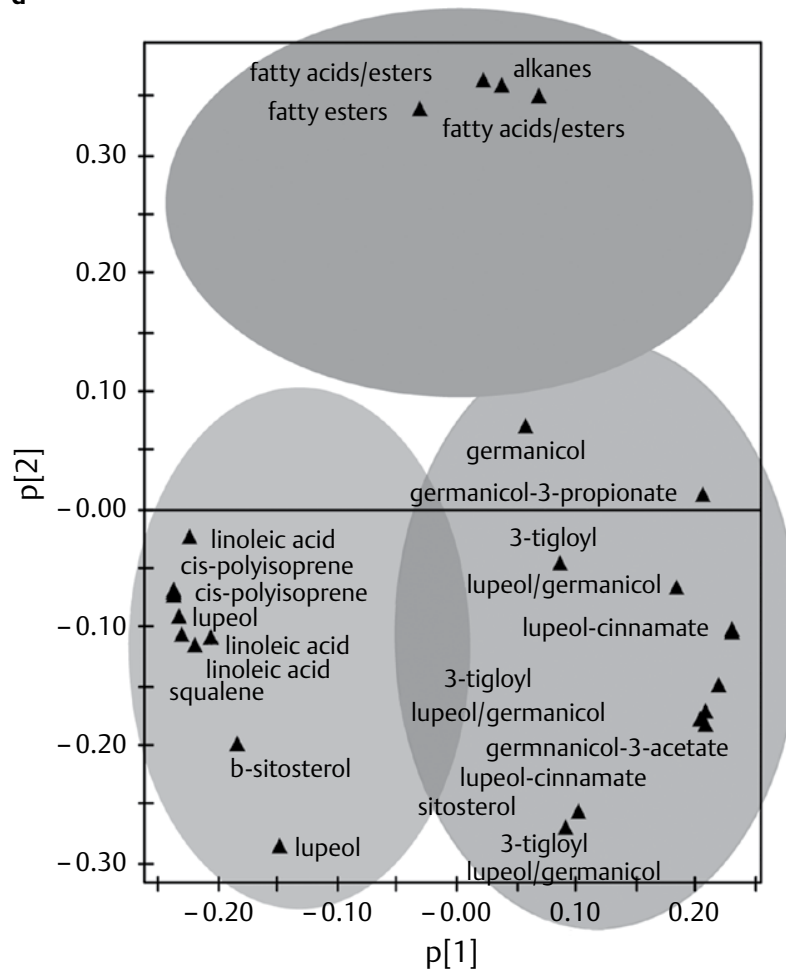

- Fig. 4 PCA of metabolites in the hexanic extract of leaves, stems, and fruits of A. sericifera analyzed by GC-MS and ${ }^{13} \mathrm{C}$ NMR spectroscopy. a Score plot of GC-MS analysis, 2 components R2X (cum) $=0.89$, Q2 (cum) $=0.79$. b Loading plot of GC-MS analysis. c Score plot of ${ }^{13} \mathrm{C} \mathrm{NMR}$ analysis 2 components R2X (cum) $=0.87, \mathrm{Q} 2$ (cum) $=0.77$. $\mathbf{d}$ Loading plot of ${ }^{13} \mathrm{C}$ NMR analysis.

\section{Plant material}

Aerial parts of A. sericifera (leaves, stems, and fruits) were harvested in September 2014 from adult plants that grew in an open field located in Moncófar (Castellón, eastern Spain). The botanical characterization of the plant was carried out by Prof. Herminio Boira from the Mediterranean Agroforesty Institute of the Polytechnic University of Valencia, and a voucher specimen was deposited at the VALA herbarium of the University Polytechnic of Valencia (Spain) with the registration number 6647.

\section{Extraction and isolation}

Oven-dried leaves, stems, and fruits were separated from each plant and, in addition, the fruits were cut and seeds removed. These aerial organs were finely powdered in a mechanical grinder and extracted by an automatic Soxhlet in a Foss Tecator Soxtec ${ }^{\mathrm{TM}}$ system with a 2043 extraction unit and a 2046 Soxtec Foss Control unit. Each sample $(5 \mathrm{~g})$ was firstly extracted with $\mathrm{n}$-hexane $(50 \mathrm{~mL})$ for $1 \mathrm{~h} 30 \mathrm{~min}$ of boiling time and $20 \mathrm{~min}$ of rising time, followed by $\mathrm{MeOH}(50 \mathrm{~mL})$ under the same operating conditions [30]. The solvents were evaporated under reduced pressure to obtain the hexanic and methanolic extracts. 
a $\triangle$ fruit leaf stem

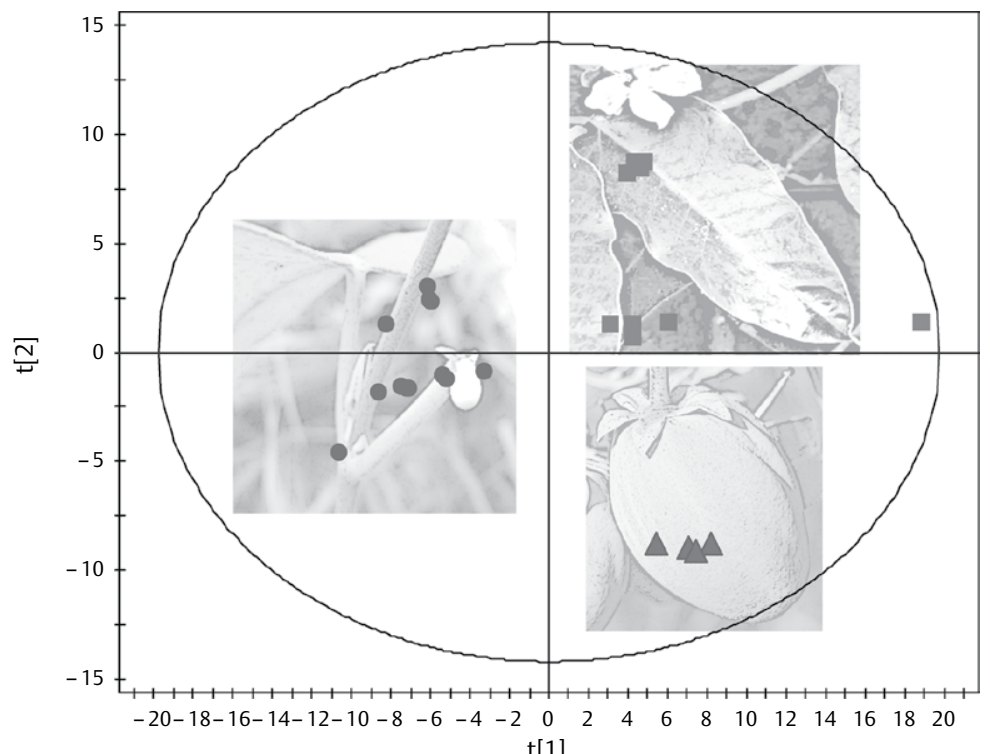

$\mathrm{t}[1]$

b

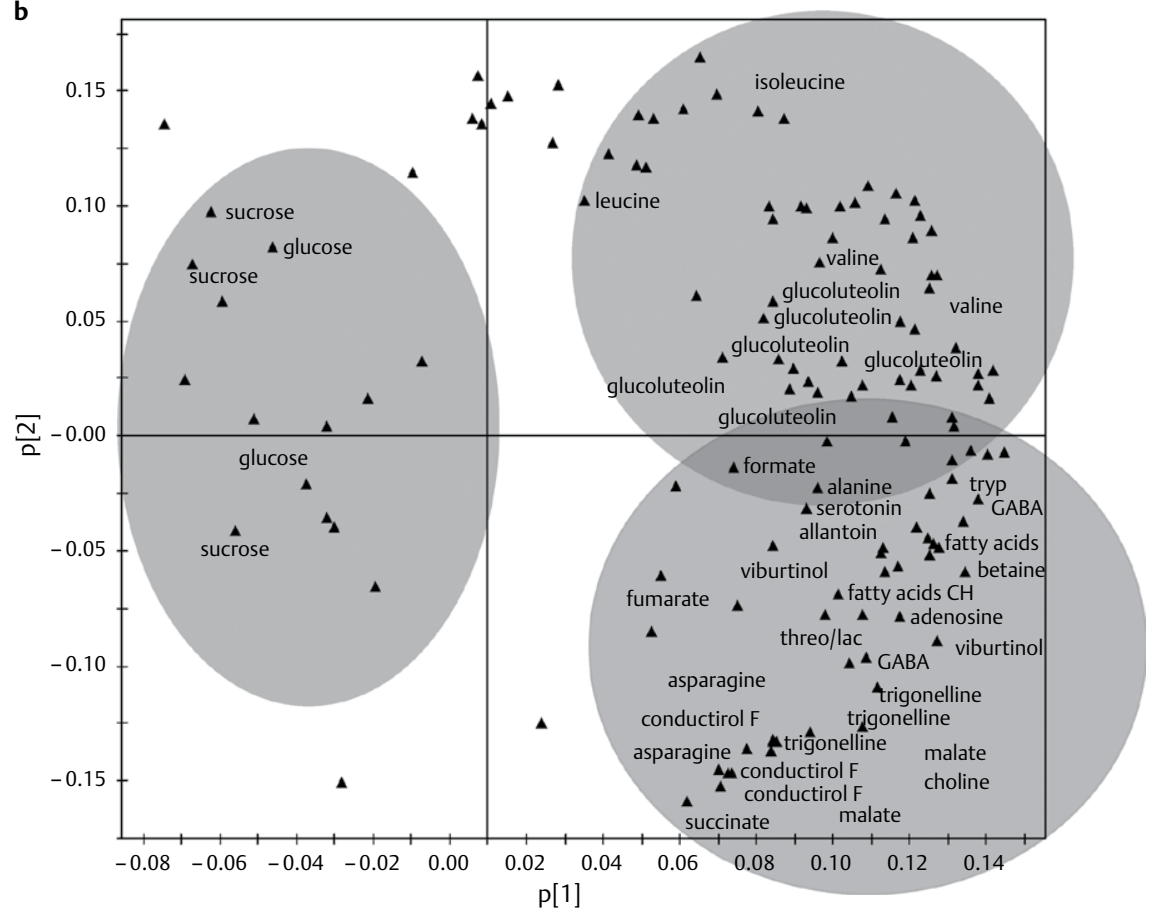

Fig. 5 Multivariate analysis of ${ }^{1} \mathrm{H}$ NMR spectra of polar methanolic extracts of $A$. sericifera, an unsupervised PCA model. a Score plot: two components R2X (cum) $=0.63$, Q2 (cum) $=0.46$. b Loading plot.

Dry leaf hexanic extracts $(100 \mathrm{mg})$ were dissolved in $\mathrm{MeOH}$ $(4 \mathrm{~mL})$ and centrifuged at $3000 \mathrm{rpm}$ for $8 \mathrm{~min}$ at $22^{\circ} \mathrm{C}$ in order to partially remove the rubber content. The supernatant was separated and the pellet was dissolved in $\mathrm{MeOH}(4 \mathrm{~mL})$ and then centrifuged again. This $\mathrm{MeOH}$ centrifugation procedure was performed three times for each sample [10]. The supernatants were combined and dried by nitrogen stream to give a residue of leaf hexanic extract $(100 \mathrm{mg})$ that was subjected to flash column chromatography on silica gel $60(40-63 \mu \mathrm{m})$ using a stepwise gradient soln. solution from $100 \%$ hexane to $100 \%$ ethyl acetate and yielding five fractions. The major fraction F-2 (hexane/EtOAc, 9:1, $13 \mathrm{mg}$ ) was purified by a semipreparative reversed-phase HPLC instrument (Waters $600 \mathrm{E}$ system) equipped with a solvent delivery pump unit (Waters $600 \mathrm{E}$ ) coupled to a photodiode array detector (Waters 2996 PDA) and an evaporative light scattering detector (Waters 2420 ELSD). The separation of metabolites was carried out using a Phenomen- 


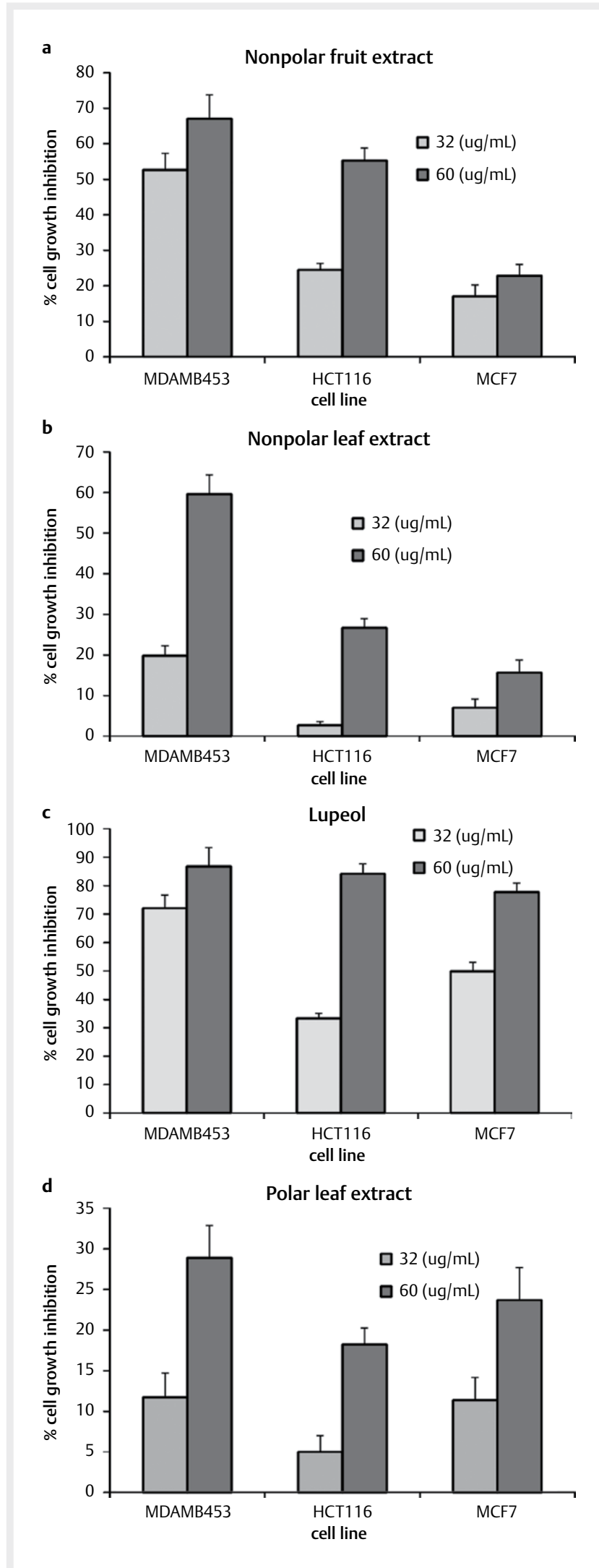

- Fig. 6 Cell growth inhibition obtained by the MTS assay against three different cell lines at two different concentrations. ex Luna C18 (2) column $(25.0 \times 1 \mathrm{~cm}, 5 \mu \mathrm{m})$ and $100 \%$ methanol as the mobile phase (flow of $3 \mathrm{~mL} / \mathrm{min}$ ) to afford $\mathrm{SF}_{\text {hex }} 2-1$ ( $\mathrm{t}_{\mathrm{R}}=30 \mathrm{~min}$ ), $S F_{\text {hex }} 2-2\left(t_{R}=35 \mathrm{~min}\right), S_{\text {hex }} 2-3\left(t_{R}=42 \mathrm{~min}\right), \mathrm{SF}_{\text {hex }} 2-4\left(\mathrm{t}_{R}=45 \mathrm{~min}\right)$, $\mathrm{SF}_{\text {hex }} 2-5\left(\mathrm{t}_{\mathrm{R}}=48 \mathrm{~min}\right)$, and $\mathrm{SF}_{\text {hex }} 2-6\left(\mathrm{t}_{\mathrm{R}}=52 \mathrm{~min}\right)$. On the other hand, a residue of the fruit methanolic extract $(85 \mathrm{mg})$ was subjected to the solid-phase extraction (SPE) $\mathrm{C}_{18}$ cartridge $(2 \mathrm{~g}, 12 \mathrm{ml}$ ) model ExtraBond (Scharlab) with $100 \% \mathrm{H}_{2} \mathrm{O}$ followed by $100 \% \mathrm{MeOH}$. Fraction $\mathrm{F}-2(100 \% \mathrm{MeOH})$ was purified by semipreparative reversed-phase HPLC using a Phenomenex Luna C18 (2) column $(25.0 \times 1 \mathrm{~cm}, 5 \mu \mathrm{m})$ and $100 \% \mathrm{H}_{2} \mathrm{O}$ as the mobile phase (flow of $3 \mathrm{~mL} / \mathrm{min}$ ) to afford the $\mathrm{SF}_{\text {meth }} 2-1\left(\mathrm{t}_{\mathrm{R}}=6 \mathrm{~min}\right), \mathrm{SF}_{\text {meth }} 2-2\left(\mathrm{t}_{\mathrm{R}}=9 \mathrm{~min}\right)$, and $\mathrm{SF}_{\text {meth }} 2-3\left(\mathrm{t}_{\mathrm{R}}=11 \mathrm{~min}\right)$. All purified fractions from both hexanic and methanolic extracts were dried, derivatized, and analyzed by GC-MS and NMR spectroscopy.

3-O-Tigloyl germanicol (18): white amorphous powder; m.p. 244-249 ${ }^{\circ} \mathrm{C} ;[\alpha]_{\mathrm{D}}{ }^{25}+27.2$ (c 0.5, $\mathrm{CHCl}_{3}$ ); IR (film): 2940, 1710, 1634, $1446 \mathrm{~cm}^{-1} ;{ }^{1} \mathrm{H}$ and ${ }^{13} \mathrm{C}$ NMR, see $>$ Table $1 ;$ HRESIMS m/z 409.3832 $\left[\left(\mathrm{M}-\mathrm{C}_{5} \mathrm{H}_{7} \mathrm{O}-\mathrm{H}_{2} \mathrm{O}\right)+\mathrm{H}\right]^{+}$(calcd. for $\left.\mathrm{C}_{30} \mathrm{H}_{48}, 409.3829\right)$.

3-O-Tigloyl lupeol (19): white amorphous powder; m.p. 233$237^{\circ} \mathrm{C} ;[\alpha]_{\mathrm{D}} 25+42.5$ (c $\left.0.5, \mathrm{CHCl}_{3}\right) ; \mathrm{IR}$ (film): 2987, 1710, 1654 , $1457 \mathrm{~cm}^{-1} ;{ }^{1} \mathrm{H}$ and ${ }^{13} \mathrm{C}$ NMR, see $>$ Table 1 ; HRESIMS m/z 409.3829 $\left[\left(\mathrm{M}-\mathrm{C}_{5} \mathrm{H}_{7} \mathrm{O}-\mathrm{H}_{2} \mathrm{O}\right)+\mathrm{H}\right]^{+}$(calcd. for $\left.\mathrm{C}_{30} \mathrm{H}_{48}, 409.3829\right)$.

\section{Derivatization and GC-MS analysis}

Samples of the hexanic extracts were derivatized according to Van Beek [31]. Trimethylsilyl derivatives of hexanic extract samples $\left(5 \mathrm{mg}\right.$ ) were prepared by the addition of $100 \mu \mathrm{L}$ of dry $\mathrm{CH}_{2} \mathrm{Cl}_{2}$ and $100 \mu$ l of BSTFA with $1 \%$ TMCS. Next, the mixture was stirred overnight at room temperature. Samples of the methanolic extracts were derivatized according to Herebian et al. [32]. Derivatives of the methanolic extracts were prepared by a two-step procedure involving a methoximation-trimethylsilylation process. For methoximation, the extract samples $(5 \mathrm{mg})$ were treated with methoxyamine hydrochloride soln. solution ( $20 \mathrm{mg} \mathrm{mL}^{-1}$ in pyridine $)(100 \mu \mathrm{L})$ and stirred overnight at room temperature. Next, BSTFA with $1 \%$ TMCS $(100 \mu \mathrm{L})$ was added as a silylation reagent and stirred for $3 \mathrm{~h}$ at room temperature. Derivatized samples were directly analyzed by GC-MS on a PerkinElmer Clarus ${ }^{\circledR} 500$ gas chromatograph-mass spectrometer, operating in the electron impact mode (EI) and equipped with a ZB- $5 \mathrm{MS}(30 \mathrm{~m} \times 0.25 \mathrm{~mm} \times 0.25 \mu \mathrm{m}$ particle size $)$ capillary column (Phenomex Inc). GC-MS parameters, peaks identification, and quantification procedure are described in more detail in the Supporting Information.

\section{UPLC-Q-TOF analysis}

High-resolution mass (HRESIMS) spectra for the new compounds were obtained from a Triple TOFTM 5600 hybrid quadrupole timeof-flight (TOF) LC-MS/MS system (AB SCIEX) and a Waters Acquity BEH C1 8 column $(50 \times 2.1 \mathrm{~mm}$ i.d., $1.7 \mu \mathrm{m})$. UPLC-Q-TOF parameters are described in more detail in the Supporting Information.

\section{General procedure for the preparation of 3-tigloyl lupeol (19)}

The esterification procedure was carried out according to Liu et al. [33]. Lupeol (6.0 mg, 1 equiv) was added to a soln. solution of trans2-methyl-2-butenoic acid ( $1.4 \mathrm{mg}, 1$ equiv), DCC ( $5.8 \mathrm{mg}, 2$ equiv), and DMAP (3.4 mg, 2 equiv) in dry $\mathrm{CH}_{2} \mathrm{Cl}_{2}(2 \mathrm{ml})$, and the reaction 
mixture was shaken for $24 \mathrm{~h}$. Next, the solvent was removed under reduced pressure to give a white solid that was redissolved in $\mathrm{CH}_{2} \mathrm{Cl}_{2}$, washed with $5 \% \mathrm{NaHCO}_{3}$, dried over $\mathrm{Na}_{2} \mathrm{SO}_{4}$, and concentrated under reduced pressure to obtain a crude residue. The residue was purified by semipreparative reverse-phase HPLC-PDA-ELSD using a Phenomenex Luna C18 (2) column $(25.0 \times 1 \mathrm{~cm}, 5 \mu \mathrm{m})$ and $100 \%$ methanol as the mobile phase with a flow rate of $3 \mathrm{~mL} \mathrm{~min}{ }^{-1}$. 3-O-Tigloyl lupeol (19) was obtained in a $63 \%$ yield as white powder.

\section{NMR spectroscopy}

NMR spectra were recorded at $25^{\circ} \mathrm{C}$ on a Bruker AVII-600 using a 5 -mm TCl cryoprobe $\left({ }^{13} \mathrm{C}\right.$ spectra) and a Bruker AVIII-500 using a 5-mm TBI probe (all the other experiments) and processed using Topspin 3.17 software (Bruker $\mathrm{GmbH}$ ). Nonpolar extracts $(20 \mathrm{mg}$ ) were dissolved in $500 \mu \mathrm{L}$ of $99.8 \%$ chloroform-d with $0.05 \% \mathrm{v} / \mathrm{v}$ TMS. Polar extracts were dissolved in $500 \mu \mathrm{l}$ of $50 \%$ methanol- $\mathrm{d}_{4}$ in buffer [ $90 \mathrm{mM} \mathrm{KH}_{2} \mathrm{PO}_{4}, \mathrm{pH}=6,1 \mathrm{mM}$ trimethylsilyl-2,2,3,3-tetradeuteropropionic acid (TSP)]. Chemical shifts $(\delta)$ of ${ }^{1} \mathrm{H}$ and ${ }^{13} \mathrm{C}$ NMR are given in ppm. The acquisition parameters of NMR spectra and quantification procedure are described in more detail in the Supporting Information.

\section{Principal component analysis}

Variable sized bucketing was performed of the ${ }^{1} \mathrm{H}$ and ${ }^{13} \mathrm{C}$ NMR spectra, excluding the regions corresponding to $\mathrm{CDCl}_{3}$ (in nonpolar samples) and to $\mathrm{D}_{2} \mathrm{O}$ and $\mathrm{MeOD}$ resonances (in polar samples). After normalization and univariate scaling, data were subjected to $P C A$, an unsupervised pattern recognition method [34], using the software Simca-P+12.0. PCA score plots show clustering trends between samples, how metabolite concentrations are related, and if there are any strong outliers. The discriminant metabolites were identified from the corresponding loading plots.

\section{MTS [3-(4,5-dimethylthiazol-2-yl)-5-(3- carboxymethoxyphenyl)-2-(4-sulfophenyl)-2H- tetrazolium]assay with cancer model cell lines}

The effect of organic leaf, fruit, and stem extracts and lupeol (purity $\geq 94 \%$; Sigma), lupeol-cinnamate, and 3-O-tigloyl lupeol compounds was evaluated by the standard procedure of the MTS [3-(4,5-dimethylthiazol-2-yl)-5-(3-carboxymethoxyphenyl)-2-(4sulfophenyl)-2H-tetrazolium] cell viability assay [35] in HCT-116, MFC-7, and MDA-MB-453 cells lines. A stock solution of extracts and compounds $(2 \mathrm{mg} / \mathrm{mL}$ ) in DMSO was prepared. This stock solution was diluted in culture medium (DMEM for HCT-116 and MFC7, or DMEM/F12 for MDA-MB-453) to obtain of 32, 64, 96, and $120 \mu \mathrm{g} / \mu \mathrm{L}$ solutions (DMSO, maximal concentration $0.1 \%$ ). A solution of medium containing only DMSO at $0.1 \%$ was also prepared. Cells were harvested in their logarithmic phase and seeded at concentrations of 12500 (HCT-116), 5000 (MCF-7), and 10000 (MDAMB-116) cells per well in 96-well microtiter plates and incubated for $18 \mathrm{~h}$ in $50 \mu \mathrm{L}$ of their respective media at $37^{\circ} \mathrm{C}$ and $5 \% \mathrm{CO}_{2}$. Cells were then observed under a light microscope $(20 \times)$ to check if they were attached to the plates. Fifty $\mu \mathrm{L}$ of medium were added with the absence (only DMSO at a final concentration of $0.05 \%$ ) or presence of compounds/extracts to yield final compound/extract concentrations of $16,32,48$, and $60 \mu \mathrm{g} / \mu \mathrm{L}$ per well, and cells were in- cubated for $72 \mathrm{~h}$. MTS was freshly prepared at $5 \mathrm{mg} / \mathrm{mL}$ in PBS, and $20 \mu \mathrm{L}$ of a mixture of MTS solution and phenazine methosulfate (20:1) were added to each well and incubated at $37{ }^{\circ} \mathrm{C}$ for another $3 \mathrm{~h}$. Finally, the absorbance was measured with a spectrophotometer (VICTOR2 1420 Multilabel HTS Counter) at $595 \mathrm{~nm}$. Results are the mean of three independent experiments $(n=3)$.

Supporting information: Details on extraction and properties of the extracts are available as Supporting Information.

\section{Acknowledgments}

This research was supported by the Spanish Government (Secretaría de Estado de Investigación, Desarollo e Innovación, Ministerio de Economía y Competitividad) with the project SAF2014-53977-R, the Spanish Ministry of Economy and Competitiveness through a Miguel Servet Program (CP15/00150) ISCIII (Carlos III Institute of Health), co-funded by the European Fund for Regional Development (FEDER) and European Social Fund (ESF), and also the Cemex Sustainable Chair in Spain for the doctoral fellowship to P. V. E. The work was undertaken as part of the COST Action CA15135. We are grateful to the Colombian Government's Department of Science, Technology and Administration (COLCIENCIAS) for providing a doctoral fellowship (The Francisco Jose de Caldas Program) to M. C. M. We also thank A. Fernández (Bruker) and E. Mateos (ITQ) for technical NMR support. The authors would also like to acknowledge $M$. Orzáez (CIPF) for kindly providing the cancer tumor cells, and M. $\mathrm{H}$. Ferrandis (CIPF) and L. Orti (CIPF) for help with the cell culture experiments.

\section{Conflict of Interest}

The authors declare no conflict of interest.

References

[1] Spellman DL, Gunn CR. Morrenia odorata and Araujia sericofera (Asclepiadaceae): weeds in citrus groves. Castanea 1976; 41: 139-148

[2] Forster PI, Bruyns PV. Clarification of synonomy for the common mothvine Araujia sericifera (Asclepiadaceae). Taxon 1992; 41: 746-749

[3] Federici E, Galeffi C, Nicoletti M. Constituents of Araujia sericofera. J Nat Prod 1988; 51: 189-190

[4] López de Medrano-Villar M], Bello R, Esplugues J et al. Triterpenoid compounds from Araujia sericofera B. Effects on the isolated guinea pig ileum. Methods Find Exp Clin Pharmacol 1997; 19: 515-520

[5] Bello R, Barrachina MD, Esplugues ] et al. Analgesic activity and effects on isolated smooth muscle of different fractions of hexane extract from Araujia sericofera Brot. Phytother Res 1996; 10: 337-339

[6] Matsuda F, Yonekura-Sakakibara K, Niida R et al. MS/MS spectral data tag-based annotation of non-targeted profile of plant secondary metabolites. Plant J 2009; 57: 555-577

[7] Frederich M, Choi YH, Angenot L et al. Metabolomic analysis of Strychnos nux-vomica, Strychnos icaja and Strychnos ignatii extracts by $1 \mathrm{H}$ nuclear magnetic resonance spectrometry and multivariate analysis techniques. Phytochem 2004; 65: 1993-2001 
[8] Barding GA, Béni S, Fukao T et al. Comparison of GC-MS and NMR for metabolite profiling of rice subjected to submergence stress. J Proteome Res 2013; 12: 898-909

[9] Sholichin M, Yamasaki K, Kasai R et al. 13C Nuclear magnetic resonance of lupane-type triterpenes, lupeol, botulin and betulinic acid. Chem Pharm Bull 1980; 28: 1006-1008

[10] Palomino-Schätzlein M, Escrig PV, Boira $\mathrm{H}$ et al. Evaluation of nonpolar metabolites in plant extracts by $13 \mathrm{C}$ NMR spectroscopy. J Agric Food Chem 2011; 59: 11407-11416

[11] Ebajo VD Jr., Shen CC, Ragasa CY. Terpenoids and Sterols from Hoya multiflora Blume. J Appl Pharm Sci 2015; 5: 33-39

[12] Dat NT, Cai XF, Bae K et al. Terpenoid constituents from Youngia koidzumiana. Nat Prod Sci 2002; 8: 55-57

[13] Wood CA, Lee K, Vaisberg AJ et al. A bioactive spirolactone iridoid and triterpenoids from Himatanthus sucuuba. Chem Pharm Bull 2001; 49: 1477-1478

[14] Rojas LB, Grignon-Dubois M, Rezzonico B et al. Pentacyclic triterpenes from Sarcostemma clausum. Chem Nat Comp 2004; 40: 565-568

[15] Boutaghane N, Voutquenne-Nazabadioko L, Simon A et al. A new triterpenic diester from the aerial parts of Chrysanthemun macrocarpum. Phytochem Lett 2013; 6: 519-525

[16] Le Gall GL, Colquhoun IJ, Davis AL et al. Metabolite profiling of tomato (Lycopersicon esculentum) using $1 \mathrm{H}$ NMR spectroscopy as a tool to detect potential unintended effects following a genetic modification. J Agric Food Chem 2003; 51: 2447-2456

[17] Abe F, Yamauchi T, Honda K et al. Conduritol F glucosides and terpenoid glucosides from Cynanchum liukiuense and distribution of conduritol $\mathrm{F}$ glucosides in several Asclepiadaceous plants. Chem Pharm Bull 2000; 48: 1090-1092

[18] Sheng H, Sun H. Synthesis, biology and clinical significance of pentacyclic triterpenes: a multi-target approach to prevention and treatment of metabolic and vascular diseases. Nat Prod Rep 2011; 28 : 543-593

[19] Papi Reddy K, Singh AB, Puri A et al. Synthesis of novel triterpenoid (lupeol) derivatives and their in vivo antihyperglycemic and antidyslipidemic activity. Bioorg Med Chem Lett 2009; 19: 4463-4466

[20] Ortiz-Andrade RR, García-Jiménez S, Castillo-España P et al. $\alpha$-Glucosidase inhibitory activity of the methanolic extract from Tournefortia hartwegiana: an anti-hyperglycemic agent. J Ethnopharmacol 2007; 109: 48-53

[21] Padilha MM, Vilela FC, Rocha CQ et al. Antiinflammatory properties of Morus nigra leaves. Phytother Res 2010; 24: 1496-1500

[22] Machado ART, Lage GA, Medeiros FS et al. Quantitative analysis of trigonelline in some Annona species by proton NMR spectroscopy. Nat Prod Bioprospect 2013; 3: 158-160
[23] Angelaud R, Babot O, Charvat T et al. Desymmetrization of cyclohexadienylsilanes. Regio-, diastereo-, and enantioselective access to sugar mimics. J Org Chem 1999; 64: 9613-9624

[24] Worawalai W, Rattanangkool E, Vanitcha A et al. Concise synthesis of $(+)$-conduritol $\mathrm{F}$ and inositol analogues from naturally available (+)-proto-quercitol and their glucosidase inhibitory activity. Bioorg Med Chem Lett 2012; 22: 1538-1540

[25] Benavente-García O, Castillo J, Lorente J et al. Antioxidant activity of phenolics extracted from Olea europaea L. leaves. Food Chem 2000; 68: 457-462

[26] Gutiérrez-Nicolás F, Gordillo-Román B, Oberti JC et al. Synthesis and anti-HIV activity of lupane and olean-18-ene derivatives. Absolute configuration of 19,20-epoxylupanes by VCD. J Nat Prod 2012; 75: 669-676

[27] Liu Y, Tingting B, Wang G et al. Lupeol inhibits proliferation and induces apoptosis of human pancreatic cancer PCNA-1 cells through AKT/ERK pathways. Naunyn-Schmiedeberg's Arch Pharmacol 2015; 388: 295-304

[28] Hwang Y], Lee E], Kim HR et al. Molecular mechanisms of luteolin 7-O-glucoside-induced growth inhibition on human liver cancer cells: G2/M cell cycle arrest and caspase-independent apoptotic signaling pathways. BMB Rep 2013; 46: 611-616

[29] Andreu-Fernández V, Sancho M, Genovés A et al. Bax transmembrane domain interacts with prosurvival $\mathrm{Bcl}-2$ proteins in biological membranes. PNAS 2007; 114: 313-315

[30] Nyström L, Lampi AM, Rita $\mathrm{H}$ et al. Effects of processing on availability of total plant sterols, steryl ferulates and steryl glycosides from wheat and rye bran. J Agric Food Chem 2007; 55: 9059-9065

[31] Van Beek TA. Chemical analysis of Ginkgo bioloba leaves and extracts. J Chromatogr A 2002; 967: 21-55

[32] Herebian D, Hanisch B, Marner F]. Strategies for gathering structural information on unknown peaks in the GC/MS analysis of Corynebacterium glutamicum cell extracts. Metabolomics 2005; 1: 317-324

[33] Liu XK, Ye B], Wu Y et al. Synthesis and anti-tumor evaluation of panaxadiol derivatives. Eur J Med Chem 2011; 46: 1997-2002

[34] Jackson JE. A user's guide to principal components. New York: Wiley; 1991

[35] Barltrop JA, Owen TC, Cory AH et al. 5-(3-Carbomethoxyphenyl)2-(4,5-dimethylthiazolyl)-3-(4-sulfophenyl)tetrazolium, inner salt (MTS) and related analogs of 3-(4,5-dimethylthiazolyl)-2,5-diphenylterazolium bromide (MTT) reducing to purple water-soluble formazans as cell viability indicators. Bioorg Med Chem Lett 1991; 1: 611-614 